\title{
Avaliação da prática da higienização das mãos em tempos de pandemia
}

\section{Evaluation of hand hygiene practice in pandemic times}

DOI: $10.46919 / \operatorname{archv} 2 \mathrm{n} 3-017$

Recebimento dos originais: 01/01/2021

Aceitação para publicação: 31/03/2021

\section{Shayane Kelly Gomes Rufino}

Acadêmica do Curso de Farmácia da Faculdade Aggeu Magalhães - FAMA e membro da Liga Acadêmica de Ensino em Saúde e Pesquisa - LAESP, Serra Talhada - PE, Brasil.

\section{Kayo Katchman Leite Ferreira}

Acadêmicos do Curso de Enfermagem da Faculdade Aggeu Magalhães -FAMA e membros da Liga Acadêmica de Ensino em Saúde e Pesquisa - LAESP,Serra Talhada -PE, Brasil.

\section{Ayza Fernanda da Silva Souza}

Acadêmicos do Curso de Enfermagem da Faculdade Aggeu Magalhães -FAMA e membros da Liga Acadêmica de Ensino em Saúde e Pesquisa - LAESP,Serra Talhada -PE, Brasil.

\section{Edivaldo Lourival Gaia Júnior}

Acadêmicos do Curso de Enfermagem da Faculdade Aggeu Magalhães -FAMA e membros da Liga Acadêmica de Ensino em Saúde e Pesquisa - LAESP,Serra Talhada -PE, Brasil.

\section{Thalia Lima Nogueira}

Acadêmicos do Curso de Enfermagem da Faculdade Aggeu Magalhães -FAMA e membros da Liga Acadêmica de Ensino em Saúde e Pesquisa - LAESP,Serra Talhada -PE, Brasil.

\section{Raul Sousa Andreza}

Docentes e Orientadores da Liga Acadêmica de Ensino em Saúde e Pesquisa LAESP - FAMA, Faculdade Aggeu Magalhães, Serra Talhada - PE.

\section{Mário Célio Gonçalves da Silva Júnior}

Docentes e Orientadores da Liga Acadêmica de Ensino em Saúde e Pesquisa LAESP - FAMA, Faculdade Aggeu Magalhães, Serra Talhada - PE.

\section{Janete Clair da Silva Santos}

Docentes e Orientadores da Liga Acadêmica de Ensino em Saúde e Pesquisa LAESP - FAMA, Faculdade Aggeu Magalhães, Serra Talhada - PE.

\section{Amanda Raquel Novaes Gomes}

Docentes e Orientadores da Liga Acadêmica de Ensino em Saúde e Pesquisa LAESP - FAMA, Faculdade Aggeu Magalhães, Serra Talhada - PE.

\section{RESUMO}

Introdução: A higienização das mãos é uma das mais importantes medidas profiláticas contra infecções bacterianas, vírus, principalmente a Covid-19. O presente estudo avaliou a prática de higienização das mãos em profissionais em gerais. Método: trata-se de uma pesquisa de campo, observacional, com caráter quantitativo. O estudo foi realizado através do Google Forms pela Faculdade Aggeu Magalhães de Serra 
Talhada, Pernambuco do ano de 2021. O questionário compreendeu 87 entrevistados, sendo composta por diferentes categorias profissionais. A coleta de dados foi realizada no período de duas semanas sendo acompanhados diariamente os resultados. Resultados: Após a analises de dados observou que a quantidade da higienização das mãos pelos os profissionais está acima de 12 vezes com (45\%) em média 08 vezes $(35 \%)$ e em média 05 vezes $(23 \%)$. No que diz respeito aos materiais para a prática, álcool a $70 \%$ obteve $(47,1 \%)$, água e sabão $(36,8 \%)$ e álcool em gel $(16,1 \%)$. E por fim, foi avaliado o aumento da frequência da higienização das mãos em que $(79,3 \%)$ diz que concorda totalmente, $(19,5 \%)$ concorda parcialmente e $1 \%$ discorda. Conclusão: Os profissionais entrevistados higienizam as mãos de acordo com as necessidades, tentando evitar a contaminação do vírus da Covid-19 entre outros.

Palavras-chave: Higienização das mãos. Profissionais. Pandemia.

\begin{abstract}
Introduction: The hand hygiene is one of the most important prophylactic measures against bacterial infections, viruses, especially Covid-19. The present study evaluated the practice of hand hygiene in professionals in general. Method: this is a field research, observational, with a quantitative character. The study was conducted through Google Forms by the Faculdade Aggeu Magalhães of Serra Talhada, Pernambuco in the year of 2021. The questionnaire comprised 87 respondents, being composed of different professional categories. The data collection was carried out over a period of two weeks and the results were followed up on a daily basis. Results: After data analysis, it was observed that the amount of hand hygiene by professionals is over 12 times (45\%) with an average of 08 times (35\%) and an average of 05 times (23\%). Regarding the materials for the practice, $70 \%$ alcohol obtained (47.1\%), water and soap (36.8\%) and alcohol gel (16.1\%). And finally, the increase in the frequency of hand hygiene was evaluated in which $(79.3 \%)$ said they totally agree, $(19.5 \%)$ partially agree and $1 \%$ disagree. Conclusion: The interviewed professionals sanitize their hands as needed, trying to avoid the contamination of the Covid-19 virus, among others.
\end{abstract}

Keywords: Hand hygiene. Professionals. Pandemic.

\title{
1 INTRODUÇÃO
}

A enfermidade COVID-19 que tem como agente etiológico o Sars-CoV-2 foi registrada pela primeira vez na cidade chinesa de Wuhan, no mês de dezembro de 2019. Devido à alta virulência do patógeno logo a patologia começou a se disseminar para outras nações, e logo os serviços hospitalares começaram a receber um grande número de indivíduos acometidos pelo coronavírus, o que gerou uma alta demanda de admissões nos setores de terapia intensiva. (PAULA et al., 2020).

Diante disso, em 11 de março de 2020 a OMS (Organização Mundial de Saúde) declarou a COVID19 como uma doença pandêmica e mostrou as medidas preventivas e indispensáveis no combate e controle ao vírus. Entre essas medidas pode-se citar: a lavagem das mãos do modo comum, isto é, quando realizada com água e sabão, higienização das mãos com álcool em gel quando não for possível realizar a higienização já citada. Além disso, faz-se necessário evitar tocar regiões de mucosa, ao tossir ou espirrar proteger a boca com lenço, isso evita que outras pessoas tenham contato com as gotículas de salivas excretadas após tais atos. Ainda, a OMS orienta que as pessoas sempre que precisarem ir a locais públicos, tenham o cuidado 
de ficar com no mínimo um metro de distância de outra pessoa, evitar ambientes com aglomerações, bem como a utilização de máscara. (OLIVEIRA; LUCAS; IQUIAPAZA, 2020).

No Brasil esse momento pandêmico ocorre em meio a um cenário de crise político-administrativa, a qual culminou na troca de quatro ministros da saúde em pouco intervalo de tempo. Apesar de o país ter se preparado de forma precoce para o enfrentamento ao Sars-CoV-2, alguns governantes têm negado ou diminuído sua gravidade. Com a falta de posicionamento cientifico por parte do poder federal, representantes políticos dos estados e municípios têm tomado medidas mais coerentes do ponto de vista da ciência para o combate ao coronavírus. No entanto, algumas cidades abriram mão das medidas mais rígidasde distanciamento social, porém tiveram que voltar aos protocolos de segurança iniciais em decorrência daelevação dos casos da doença em discussão. É importante enfatizar que tal comportamento adotado pelo líder do poder federal, pode trazer prejuízos no que diz respeito a concepção da sociedade acerca da adoçãode medidas preventivas no enfrentamento a COVID-19. (COSTA et al., 2020).

Entre as medidas implantadas no controle de surtos de infecção relacionada à assistência a saúde, ahigienização das mãos sempre exerceu um papel preponderante. Muitos surtos são controlados após adoçãode medidas que melhoram a adesão a essa prática. Como a intervenção educacional, uso de novos produtos como álcool em gel e melhorias relacionadas ao número de vezes e à localização de lavatórios/pias. (CDC,2002; LEVIN et al., 1998; BOSZCZOWSKI et al., 2005).

Tendo em vista o atual cenário sanitário, a prática da higienização das mãos destaca-se como um dos principais meios para evitar a disseminação do coronavírus. $\mathrm{O}$ ato de lavar as mãos é uma atitude simples e eficaz para o controle da pandemia. Dessa forma evita-se a transmissão de um indivíduo para outro, além disso, inibe a contaminação para a comunidade: de casa para a escola, creche, serviço de saúde, entre outros. (GIACOMINI, 2020).

\section{MÉTODO}

Trata-se de uma pesquisa de campo, de caráter observacional, com abordagem quantitativa.

O estudo foi realizado através das plataformas Google Forms pela Liga Acadêmica de Ensino em Saúde e Pesquisa da Faculdade de Ciências Médicas Aggeu Magalhães, localizada em Serra Talhada, Pernambuco. Durante o mês de maio 2021. O estudo foi constituído por 87 entrevistados que compõe a idade, sexo, área de profissão e nível escolar ou acadêmico. Como o critério de inclusão de resultados para o estudo, o formulário ficou a mais de 15 dias ativos, seguindo todos os protocolos éticos segundo a resolução 510/2016 na qual regulamenta o agir ético em pesquisa que implica o respeito pela dignidade humana e a proteção devida aos participantes das pesquisas científicas envolvendo seres humanos (BRASIL, 2016). 
Foram utilizados instrumentos já testados e validados para registros, para avaliar a importância e a quantidade de vezes sobre a prática de higienização das mãos na pandemia Covid-19, conforme preconizado pela Agência Nacional de Vigilância Sanitária (ANVISA). Nesse instrumento (Google Forms) perguntam sobre a importância, a quantidade de vezes da higienização no âmbito do trabalho, materiais utilizados e oaumento da frequência do ato de limpeza das mãos após o inicio da pandemia.

A tubulação dos dados foi descrita através do Google Forms e Microsoft Excel 2016, dispostos em gráficos e analisados através das estatísticas descritivas.

\section{RESULTADOS E DISCUSSÕES}

Foram obtidos por meio do Google Forms 87 resultados de pessoas diferentes sobre a prática de higienização das mãos, no período de 15 dias durante o mês de maio de 2021. Sendo que 41\% das respostas os participantes tem entre 18 e 23 anos de idade, $74,7 \%$ do sexo feminino e $25,3 \%$ masculino. A maioria com $57,5 \%$ na área da saúde e em seguida $27,6 \%$ da área de humanas.

Depois que todos os entrevistados consideram muito sobre a importância da prática de higienização das mãos em tempos pandêmicos. O gráfico 1 mostra durante a jornada de trabalho, quantas vezes aproximadamente higienizam as mãos.

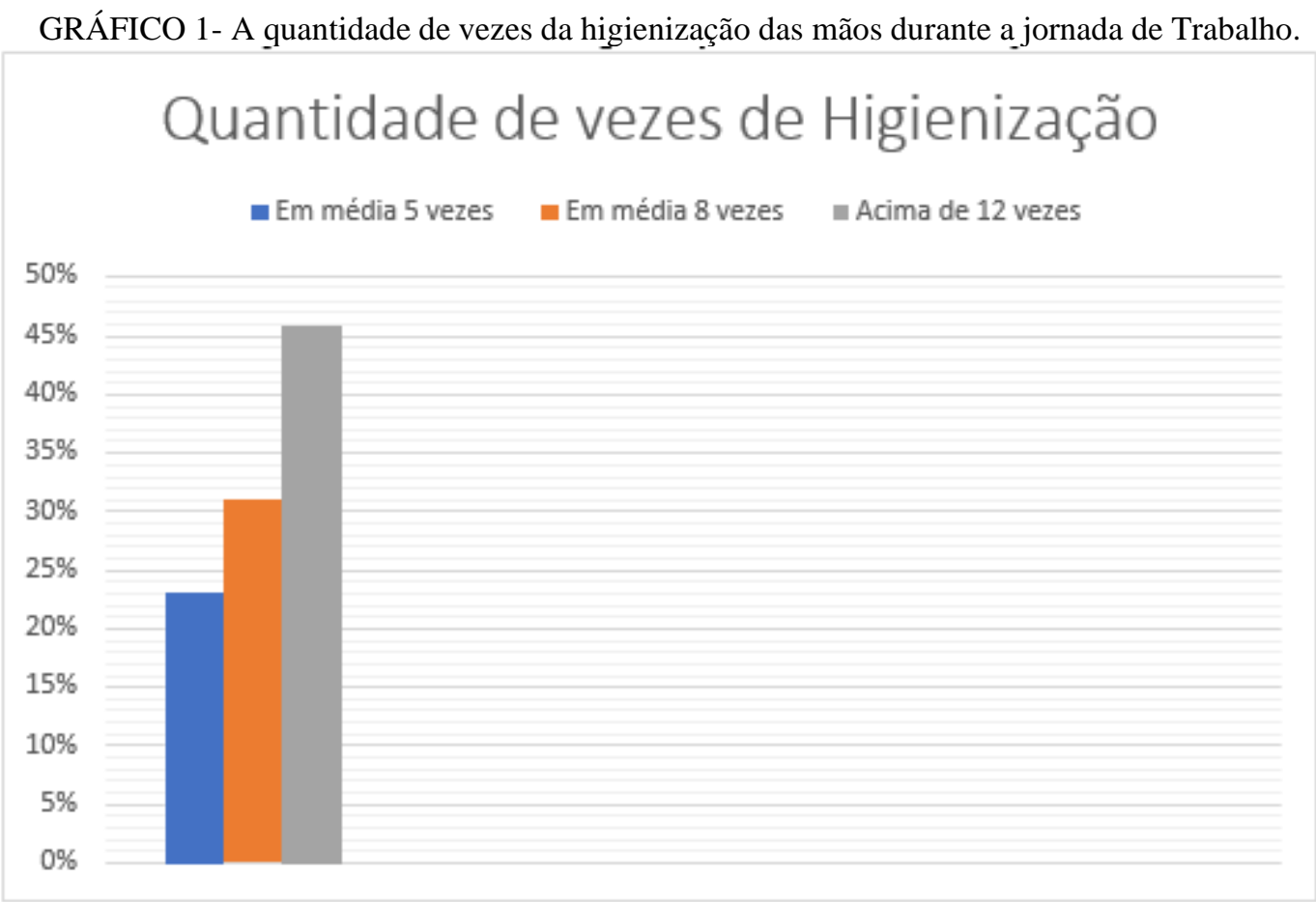

Fonte: Dados da pesquisa, 2021.

A partir desses resultados, todos os dias temos oportunidades de higienização das mãos em todos os lugares, pois, as mãos são consideradas as principais ferramentas dos profissionais que atuam 
principalmente nos serviços de saúde, é através delas que realizam suas atividades. Assim a segurança de cada um é protegida, pois em quaisquer âmbitos de trabalho depende da higienização cuidadosamente das mãos (ANIVISA, 2019).

Estudos apontam que a educação sobre a lavagem das mãos é capaz de reduzir cerca de $20 \%$ das doenças respiratórias na população em geral. E isso não é diferente para o novo coronavírus, pois essa é uma das maneiras mais eficazes de se proteger da Covid-19 (DINIZ, 2020), além do uso de máscara e o distanciamento social. Com isso, a maioria dos participantes responderam que realizada essa prática acima de 12 vezes ao dia.Além da frequência da higienização das mãos, foi perguntado também os matérias mais utilizados para a realização dessa prática, como apresentado no gráfico 2.

GRÁFICO 2- Materiais utilizados para a prática de Higienização das mãos.

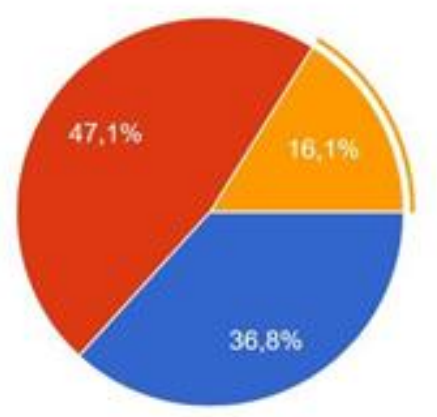

água e sabão

álccool a $70 \%$

álcool em gel

Fonte: Dados da pesquisa, 2021.

Esses materiais passaram a ser obrigatório após o início da pandemia em quaisquer estabelecimentos, hospitais, clinicas no Brasil e no mundo. Desde 1989, reconhecimento também a sua relevância, o Ministério da Saúde editou um manual "Lavar as mãos" com o objetivo de normalizar esse procedimento comum e pouco considerado no âmbito das unidades de saúde e pela população Brasileira (LARSON, 1997).

O uso de água e sabão nas mãos elimina os microrganismos transitórios e reduz os resistentes e, na maioria das vezes, interrompem a transição de várias doenças. A algum tempo, o termo "Lavagem das mãos" foi substituído por "Higienização das mãos" devido à maior abrangência deste procedimento (BRASIL, 1989). Como visto no gráfico 2 , os usos desses materiais de higiene veem sendo usado com frequência, sendo que o uso de álcool a 70\% tem maior utilização e de recuso ideal, por ser comprovado pela a ANVISA que ocorre a "morte" do Covid-19 e de outros germes. Lembrando que, não substituem a lavagem com água corrente e sabão.

O álcool em gel tem sido muito utilizado para higienização das mãos e apresentando as seguintes vantagens, é menos irritante da pele, possui maior efeito antisséptico e aplicação é rápida. Mas é importante 
salientar que é necessário lavar as mãos com água e sabão, após vários usos desse produto, quando as mãos se apresentam pegajosas (excesso de gel). (GUERRA, 2020).

Com isso, o gráfico representa que os entrevistados estão conscientes dos usos desses materiais, mostrando que como eles serão sempre importantes no dia a dia.

No terceiro e ultimo gráfico, questionou se houve um aumento da frequência do ato de higienizar as mãos após o início da pandemia Covid-19, como apresentado abaixo.

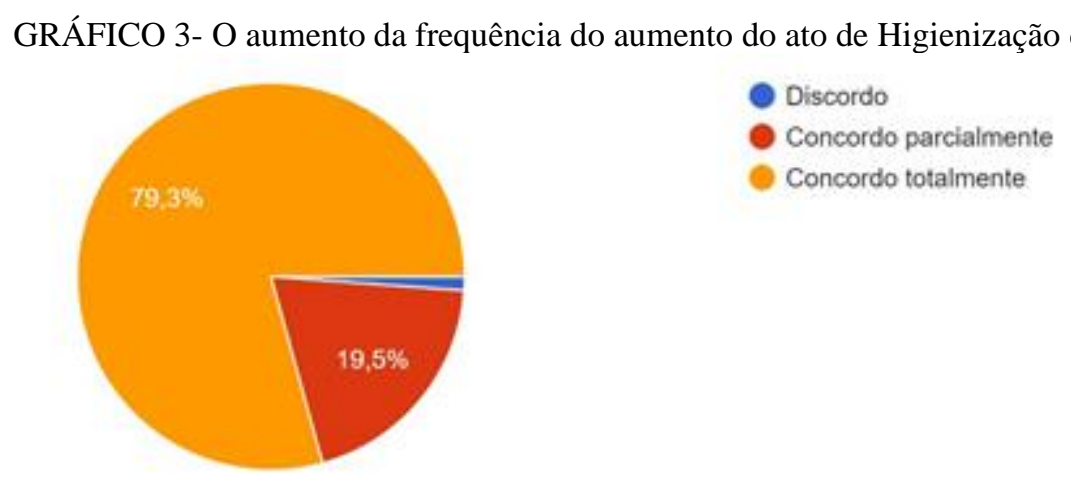

Fonte: Dados da pesquisa, 2021.

Por mais que não se tenha obtido resposta no "Discordo" comparando com 87 dados, ato de larvar as mãos são simples e ensinadas desde a infância como uma ação, principalmente de autocuidado em vários âmbitos de serviços, principalmente o de saúde, essa prática agrega produtos e técnicas que visam ampliar sua eficácia (BRASIL, 2008).

Como mostrado no terceiro gráfico, por mais que a maioria concorde totalmente o aumento dessa frequência, o procedimento dessa técnica é na maioria das vezes inadequado pelo fato do esquecimento, seja pela alta demanda do serviço (CORREA, 2001) e por pensar ou não saber que os outros materiais não substituem de forma alguma a lavagem com água e sabão.

Entretanto, desde o inicio da pandemia a população brasileira vem sendo cada vez mais educado sobre a higienização das mãos, máscaras, distanciamento social para que contenha um pouco o espalhamento do vírus. Mostrando assim, que a higienização das mãos é totalmente importante para as doenças.

\section{CONCLUSÃO}

A higienização das mãos parece um hábito fácil modificação e essa pesquisa mostra que a maioria dos profissionais entrevistados higieniza as mãos de acordo com a necessidade. Na avalição dos resultados 
permitem concluir que apesar dos contra tempo, mostra que temos uma adesão boa sobre a limpeza das mãos nos momentos necessários.

Com isso, é importante ressaltar que o uso somente de álcool a 70\% ou álcool em gel não é suficiente para eliminação dos germes, bactérias e vírus, é considerada a troca destes por água corrente e sabão sempre que for possível.

Diante dos resultados obtidos nessa pesquisa permitem concluir que a as questões apresentadas, a conscientização dos entrevistados sobre a limpeza das mãos está sendo totalmente levada a sério, tentado evitar a contrair o vírus entre outros. 


\section{REFERÊNCIAS}

BOSZCZOWSKI, I. et al. Surto de Klebsiella produtora de beta-lactamase de espectro estendido infecção por pneumoniae em unidade de terapia intensiva neonatal relacionada à onicomicose em unidade de saúde trabalhador. Pediatr Infect Dis J, Philadelphia, v. 24, n. 7, pág. 648-650, julho de 2005Brasil. Ministério da Saúde. Boletim Informativo do Ministério da Saúde. Programa de controle de infecção hospitalar. Lavar as mãos: Informações para profissionais de saúde. Brasília, 1989

Brasil. Ministério da Saúde. Agência Nacional de Vigilância Sanitária. Manual de segurança do paciente higienização das mãos em serviços de saúde. Brasília, 2008.

CDC (CENTROS DE CONTROLE E PREVENÇÃO DE DOENÇAS). Diretrizes para higiene das mãos em ambientes de saúde: recomendações do Comitê Consultivo de Práticas de Controle de Infecçãoem Saúde e a Força-Tarefa de Higiene das Mãos HICPAC / SHEA / APIC / IDSA. MMWR Recom Rep, Atlanta, v. 51, n RR-16, pág. 1-45, 2002

COSTA, Maria Fernanda Lima et al. Distanciamento social, uso de máscaras e higienização das mãos entre participantes do Estudo Longitudinal da Saúde dos Idosos Brasileiros: iniciativa ELSI-COVID-19. Cadernos de Saúde Pública, $36 \quad$ (Suppl 3), 2020. Disponível: https://www.scielosp.org/article/csp/2020.v36suppl3/e00193920/pt/

Correa I, Ranali J, Pignatari ACC. Observação do comportamento dos profissionais em relação ao procedimento da lavagem das mãos no plano assistencial à criança internada. Rev. Nursing. 2001;4(42):1821.

GIACOMINI, Maria de Lourdes. Importância da lavagem das mãos para prevenir a disseminação da COVID-19. UFRGS, 2020. Disponível: https://www.ufrgs.br/coronavirus/base/a-importancia-de-lavar-asmaos-no-combate-a-covid-19/

GUERRA, Lilia Riberito. Covid-19: como usar o álcool a 70\% e quais os riscos existentes? PREMED. Portal. 2020. Disponível: https://pebmed.com.br/covid-19-como-usar-o-alcool-a-70-e-quais-os- riscosexistentes . Acesso em 28/05/2021 Acesso em 28 de Maio 2021 às 20:00h.

Larson E, Friedman C, Cohran J, Treston-Aurand J, Green S. Prevalence and correlates of skin damage on the hands of nurses. Heart Lung: J Acute Crit Care. 1997;26(5):404-12.

Levin, A. S. et al. Fungemia de Candida parapsilosis associada a implantáveis e semi-implantáveis cateteres venosos centrais e nas mãos de profissionais de saúde. Diagn Microbiol Infect Dis, North Liberty, v. 30, n. 4, pág. 243-249, abril de 1998

OLIVEIRA, A. C.; LUCAS, T. C.; IQUIAPAZA, R. A. O que a pandemia da Covid-19 tem nos ensinado sobre a adoção de medidas de precaução? Texto \& Contexto - Enfermagem, Florianópolis, v.29, 2020. Disponível em: https://www.scielo.br/scielo.php?\%20pid=S0104-

07072020000100201\&script=sci_arttext\&tlng=pt

PAULA, Danielle Galdino de et al. Higiene das mãos em setores de alta complexidade como elemento integrador no combate do Sars-CoV-2. Revista Brasileira de Enfermagem, Brasília, v.73, 2020. Disponível em: https://www.scielo.br/scielo.php?pid=S0034-

$71672020001400151 \&$ script=sci_arttext\&tlng=pt 